\section{Creating a Comfort Environment at End-of Life in Critical Care: A Review}

Received: April 25, 2017; Accepted: May 17, 2017; Published: May 24, 2017

End-of life situations occur routinely in critical care. Depending on age and diagnosis, it is estimated that $10-29 \%$ of adults will die in the intensive care unit (ICU) [1]. When the goal of treatment changes from life-sustaining to comfort measures, it is a challenge for the staff to quickly switch gears and provide end-of-life care in an environment that is fast-paced, noisy, and even chaotic at times. This transition can be stressful for nurses and upsetting to patients and their families [2]. A review of the article "All the Comforts of Home: Transformation to a Comfort Environment in Critical Care" [3] shows how the staff of a 14-bed intensive care unit in a community hospital worked to create a peaceful, homelike atmosphere for patients and families at end-of-life.

Preparing the surroundings for comfort care should be orchestrated with grace and individualized to meet the needs of the patient and the patient's family [4]. Transforming the room starts with removing all non-essential equipment. Creating a less technical environment reduces the distance between the patient and their family [5]. The staff places a small table by the bed, topped with a soft-light lamp. Lightly scented battery operated candles are placed around the room, tempering the setting. The bed is covered with a colorful quilt and a decorated pillow sham is placed under the patient's head. The bedside monitor is changed to "comfort mode", with all alarms turned off. A compact disc player and a variety of music choices are available. The outside noise is reduced by closing the door to the room and the curtain at the end of the bed is drawn to add another layer of privacy. The result is a serene, calming environment that embraces all who enter. The effect is dramatic and the feeling of peace is tangible. The family is provided a quiet space away from the bedside, should they need respite and refreshments are provided.

Each patient's family is given a care/memory box, containing an angel pin, tissues, mints, small pouch for a lock of hair, blotter paper for thumb or finger prints, pen, notepad and a package of
Betsey S Dreher

Intensive Care Unit, Bristol Hospital, Bristol, Connecticut, USA

Corresponding author: Betsey S Dreher

bdreher@bristolhospital.org

MSN, RN, CCRN, Clinical Education

Coordinator, Intensive Care Unit, Bristol Hospital, Bristol, Connecticut, USA.

Citation: Dreher BS. Creating a Comfort Environment at End-of Life in Critical Care: A Review. J Intensive \& Crit Care 2017, 3:2.

flower seeds. These items are provided by the ICU staff, incurring no cost to the hospital. Many items can be obtained inexpensively at a discount store. Staff members have also donated more expensive items such as the quilts and pillow coverings. Recently a church confirmation class donated 25 care boxes to the ICU as their service project. Although the ICU Operations Manager is completely supportive of this process, it is staff-nurse driven. In addition, it is truly a team effort, involving all of the healthcare team, from nursing assistants to respiratory therapists.

Promoting peace during the final hours or days of a patient's life demands the best of the ICU care team [3]. The goal of the article's author was to demonstrate that this process can easily be replicated in other intensive care units, making the transition from life to death one of peace and comfort, despite being in a complex and highly technical setting. Many families have verbalized that the change in the room atmosphere made them feel like the staff cared for the family as a whole, calling the room transformation "amazing" and "truly beautiful". Staff members of the ICU have expressed feeling that it is rewarding to provide end-of-life care in such a peaceful atmosphere [4]. With a little dedication and commitment to the best in comfort care in the ICU, this process is a worthwhile endeavor. 


\section{References}

1 Society of Critical Care Medicine (2015) Society of Critical Care Medicine, ed. Critical Care Statistics.

2 Holms N, Milligan S, Kydd A (2014) A study of lived experiences of registered nurses who have provided end-of-life care within an intensive care unit. Int J Palliat Nurs 20: 549-556.
3 Cook D, Rocker G (2014) Dying with dignity in the intensive care unit. N Engl J Med 370: 2506-2514.

4 Dreher BS (2017) All the comforts of home: Transformation to a comfort environment in critical care. Crit Care Nurse 37: 78-80.

5 Efstathiou N, Walker W (2014) Intensive care nurses' experiences of providing end-of-life care after treatment withdrawal: A qualitative study. J Clin Nurs 23: 3188-3196. 